\title{
Ressenyes
}

\section{PARElla Rubio, Sònia}

\section{Mujer, inmigrante y trabajadora: la triple discriminación}

Autores, Textos y Temas. Ciencias Sociales, n. 36.

Migraciones, proyecto editorial

Barcelona: Anthropos, 2003

En el año 2003 se editó Mujer, inmigrante y trabajadora: la triple discriminación, convirtiéndose en un punto de partida para los estudios de género dentro de la sociología de las migraciones en España. La intensa experiencia como investigadora de Sònia Parella en temáticas de migración, género y políticas familiares, avalan el interesante y completo trabajo teórico y empírico que aquí se presenta. Esta obra, resultado de la investigación llevada a cabo por la autora para la realización de su tesis doctoral, tiene un doble provecho para los lectores interesados en el estudio de las migraciones. Por una parte, destaca la crítica, amplia y exhaustiva revisión teórica sobre la posición de la mujer en el fenómeno migratorio, y por otra, ofrece interesantes resultados a través de un trabajo de campo centrado en la visibilización de la discriminación que sufre la mujer inmigrante dentro del mercado laboral y, concretamente, en la masiva inserción de estas mujeres en los «servicios de proximidad» españoles.

El libro se estructura en tres grandes secciones. En la primera, se dibuja un marco teórico general para abordar el fenómeno migratorio desde una perspectiva de género, mientras que las dos últimas tratan de contextualizar y concretar el análisis del caso de las trabajadoras extranjeras en el servicio doméstico español.

La primera sección comprende una extensa revisión teórica crítica acerca del tratamiento de la mujer en las ciencias sociales. De esta forma, la autora pone de manifiesto la invisibilidad que han soportado las mujeres dentro de la producción académica general; sobre todo en lo que se refiere al importante papel que han jugado miles de mujeres protagonistas en la inmigración, donde han sido auténticas propulsoras del desarrollo económico en los países de acogida.

En la segunda sección se abordan los factores más relevantes que debemos barajar a la hora de analizar la inserción laboral de las mujeres inmigrantes en el contexto catalán y español. Una mujer, inmigrante y trabajadora debe enfrentarse a la triple discriminación (de clase, género y etnia) que rodeará su periplo migratorio y laboral en la sociedad de acogida. Así, en esta parte del libro, se profundiza en variables determinantes tales 
como las redes sociales que dirigen la ocupación de las mujeres inmigrantes en el servicio doméstico, las políticas de inmigración en España como cómplices de una migración femenina conscientemente destinada a la triple discriminación o la oferta laboral en los «servicios de proximidad» ligada a las desigualdades de género. En su conjunto, esta sección denuncia el contexto "conciliador» español que permite la perpetuación de comportamientos de desigualdad de género mediante el traspaso de las "tareas reproductivas" a otras mujeres en función de la clase social y la etnia a la que pertenecen.

En la tercera sección, se desarrolla el análisis de la investigación llevada a cabo por la autora. El análisis cualitativo, junto con la explotación estadística y bibliográfica, «destapan» la etnización de los «servicios de proximidad». En otras palabras, se hace pública la existencia de un ejército laboral, compuesto por mujeres inmigrantes, que responde de forma competitiva a las necesidades de servicio doméstico en la sociedad española. De esta manera, las mujeres inmigrantes que se emplean en "servicios de proximidad" llegan a competir e incluso a sustituir a las trabajadoras domésticas autóctonas que tradicionalmente ocupaban estos puestos de trabajo.

En conclusión, Mujer, inmigrante y trabajadora: la triple discriminación supone un punto de partida para aquellos que quieran acercarse a un estudio de las migraciones en España desde una perspectiva de género, así como un instrumento verdaderamente útil para los interesados en profundizar sobre cuestiones raramente abordadas en la sociología de las migraciones en nuestro país.

Paola Martínez 